\title{
Impact of p-AIGaN/GaN hole injection layer on GaN-based vertical cavity surface emitting laser diodes [Invited]
}

\author{
Lei Han (韩 否后) $1,2,3$, Yuanbin Gao (高元斌) ${ }^{1,2,3}$, Sheng Hang (杭 升) $)^{1,2,3}$, Chunshuang Chu (楚春双) $)^{1,2,3^{*}}$ ， \\ Yonghui Zhang (张勇辉) ${ }^{1,2,3}$, Quan Zheng (郑 权 $)^{4}$, Qing Li (李 青) $)^{4}$, and Zi-Hui Zhang (张紫辉) $)^{1,2,3^{* *}}$ \\ ${ }^{1}$ State Key Laboratory of Reliability and Intelligence of Electrical Equipment, Hebei University of Technology, Tianjin 300401, China \\ ${ }^{2}$ Key Laboratory of Electronic Materials and Devices of Tianjin, School of Electronics and Information Engineering, Hebei University of Technology, Tianjin \\ 300401, China \\ 3 Hebei Key Laboratory of Advanced Laser Technology and Equipment, Tianjin 300401, China \\ ${ }^{4}$ Key Engineering Center of Flat-Panel-Display Glass and Equipment, Shijiazhuang 050035, China
}

*Corresponding author: chuchunshuang@hotmail.com

${ }^{\star *}$ Corresponding author: zh.zhang@hebut.edu.cn

Received November 5, २०२1 | Accepted December 2, २०२1 | Posted Online January 5, २०२2

\begin{abstract}
The hole injection capability is essentially important for GaN-based vertical cavity surface emitting lasers (VCSELs) to enhance the laser power. In this work, we propose GaN-based VCSELs with the p-AIGaN/p-GaN structure as the p-type hole supplier to facilitate the hole injection. The p-AIGaN/p-GaN heterojunction is able to store the electric field and thus can moderately adjust the drift velocity and the kinetic energy for holes, which can improve the thermionic emission process for holes to travel across the p-type electron blocking layer ( $p$-EBL). Besides, the valence band barrier height in the $\mathrm{p}$-EBL can be reduced as a result of usage of the $\mathrm{p}$-AIGaN layer. Therefore, the better stimulated radiative recombination rate and the increased laser power are obtained, thus enhancing the $3 \mathrm{~dB}$ frequency bandwidth. Moreover, we also investigate the impact of the p-AIGaN/p-GaN structure with various AIN compositions in the p-AlGaN layer on the hole injection capability, the laser power, and the $3 \mathrm{~dB}$ frequency bandwidth.
\end{abstract}

Keywords: GaN-based VCSEL; hole injection; laser power; modulation response.

DOI: 10.3788/COL202220.031402

\section{Introduction}

Due to the advantages of low threshold current, single longitudinal mode output, easy process for packaging, wafer level testing, and circular output beams ${ }^{[1]}$, vertical cavity surface emitting lasers (VCSELs) have shown tremendous application potential in data communication, retinal scanning displays, medical laser, high density optical storage, printing and optical scanners, etc. ${ }^{[2-4]}$. Since the first, to the best of our knowledge, room-temperature electrically injected GaN-based VCSEL was achieved in $2008^{[5]}$, great efforts have been made to achieve better lasing performance for GaN-based VCSELs ${ }^{[6-8]}$. However, the development of GaN-based VCSELs still faces quite a few challenges. One of the obstacles that hinder the lasing performance is lateral optical mode confinement. Lateral optical mode confinement can be realized by using the buried $\mathrm{SiO}_{2}$ layer below indium-tin-oxide (ITO), where the design can also reduce the internal loss ${ }^{[9]}$. However, an even easier method to achieve the lateral mode confinement is locally varying the cavity length, and therefore a nano-height cylindrical waveguide structure has been reported ${ }^{[10]}$. Another obstacle that hinders the improvement for the laser power is low hole injection, which arises from the current crowding effect at the aperture periphery and the hole blocking effect by the p-AlGaN electron blocking layer (p-EBL). For the purpose of shaping the current paths for VCSELs, a tunnel-junction VCSEL and a VCSEL with a $\mathrm{p}-\mathrm{GaN} / \mathrm{n}-\mathrm{GaN} / \mathrm{p}-\mathrm{GaN}$ structured current spreading layer are proposed to increase the current injection into the aperture ${ }^{[11,12]}$. Besides, the AlGaN/GaN multiple-quantum-barrier structured p-EBL and Al composition-graded p-EBL have been reported, which can promote the hole injection efficiency by reducing the valence band barrier height of $\mathrm{p}-\mathrm{EBL}^{[13,14]}$.

Besides shaping the current flow paths and reducing the valence band barrier height, the hole injection efficiency can also be effectively improved by increasing the kinetic energy of the holes. Therefore, in this work, we propose a $\mathrm{p}-\mathrm{AlGaN} / \mathrm{p}-\mathrm{GaN}$ structure as the p-type hole injection layer [see Fig. 1(b)]. The negative polarization induced sheet charges at the p-AlGaN/ $\mathrm{p}-\mathrm{GaN}$ interface enhance the electric field intensity in the p-GaN layer, which will increase the drift velocity and kinetic 


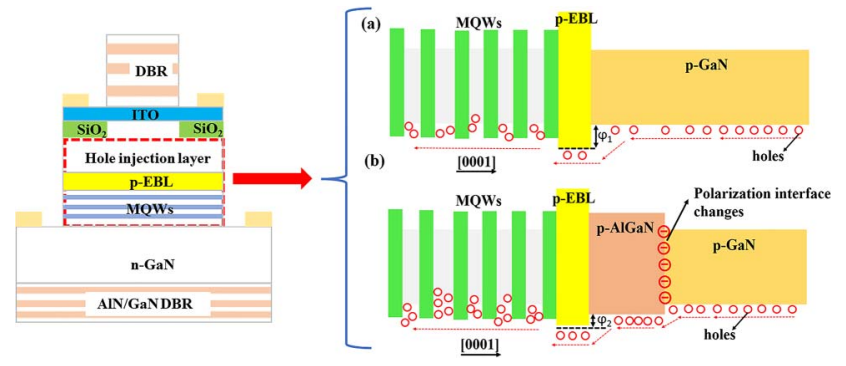

Fig. 1. Schematic diagrams for (a) the conventional InGaN/GaN VCSEL and (b) the InGaN/GaN VCSEL with a p-AIGaN/p-GaN structured p-type hole injection layer, in which polarization induced sheet charges exist at the p-AIGaN/ $\mathrm{p}$-GaN interface. The $\varphi_{1}$ and $\varphi_{2}$ denote the barrier heights at p-EBL/p-GaN and $\mathrm{p}$-EBL/p-AIGaN interfaces, respectively.

energy of the holes [see Fig. 1(b)]. Besides, the usage of the p-AlGaN layer can also reduce the valence band barrier height in the p-EBL [see Figs. 1(a) and 1(b)]. Therefore, the holes can easily cross over the valence band of the p-EBL after obtaining more kinetic energy from the $\mathrm{p}-\mathrm{AlGaN} / \mathrm{p}-\mathrm{GaN}$ structure, which results in the increased hole concentration within the multiple quantum wells (MQWs). Then, the improved hole concentration will correspondingly enhance the stimulated radiative recombination rate and then the laser power for VCSELs. Moreover, the enhanced stimulated radiative recombination rate indicates the reduced differential carrier lifetime, and this helps to increase the $3 \mathrm{~dB}$ frequency bandwidth. Detailed analysis will be discussed subsequently.

\section{Device Structure}

We design different GaN-based VCSELs to better explore the impact of the p-AlGaN/p-GaN structured p-type hole injection layer on the hole injection capability. The conventional GaNbased VCSEL is designed for comparison, as shown in Fig. 1(a), which is composed of a 28-pair AlN/GaN bottom distributed Bragg reflector (DBR), a $7 \lambda$-thick cavity, and a seven-pair $\mathrm{SiO}_{2} / \mathrm{Ta}_{2} \mathrm{O}_{5}$ top DBR. The $\lambda$ is the targeted lasing wavelength of $450 \mathrm{~nm}$. The device structure between the bottom and top DBRs consists of an $\mathrm{n}-\mathrm{GaN}$ layer $(880 \mathrm{~nm})$ with the Si doping concentration of $5 \times 10^{18} \mathrm{~cm}^{-3}$, five pairs of $\operatorname{In}_{0.21} \mathrm{Ga}_{0.79} \mathrm{~N}$ $(3 \mathrm{~nm}) / \mathrm{GaN}(4 \mathrm{~nm}) \mathrm{MQWs}$, a $\mathrm{p}-\mathrm{Al}_{0.2} \mathrm{Ga}_{0.8} \mathrm{~N}(20 \mathrm{~nm}) \mathrm{p}$-EBL, a p-GaN layer $(240 \mathrm{~nm})$, and a 20 -nm-thick ITO current spreading layer. Meanwhile, a 20-nm-thick $\mathrm{SiO}_{2}$ is buried below ITO to obtain lateral optical and electrical confinement due to the small refractive index and insulation characteristics. The radii of the $\mathrm{SiO}_{2}$ aperture and the mesa of the VCSELs are designed to be $4 \mu \mathrm{m}$ and $6.5 \mu \mathrm{m}$, respectively. The conventional VCSEL is called VCSEL A. The proposed VCSELs (VCSELs B1 to B3) are identical to VCSEL A except that the 240-nm-thick p-GaN hole injection layer is replaced by the $\mathrm{p}-\mathrm{Al}_{x} \mathrm{Ga}_{1-x} \mathrm{~N} / \mathrm{p}-\mathrm{GaN}$ $(50 \mathrm{~nm} / 190 \mathrm{~nm})$ structure in Fig. 1(b). Considering the Mg ionization rate and the Poole-Frenkel effect, the free hole concentration in both the $\mathrm{p}-\mathrm{Al}_{x} \mathrm{Ga}_{1-x} \mathrm{~N}$ and $\mathrm{p}-\mathrm{GaN}$ layers is set to
Table 1. Different AIN Compositions of the $\mathrm{p}-\mathrm{Al}_{x} \mathrm{Ga}_{1-x} \mathrm{~N}$ Layer for VCSELS B1 to B3.

\begin{tabular}{lccc}
\hline Devices & VCSEL B1 & VCSEL B2 & VCSEL B3 \\
\hline AlN composition $(x)$ & 0.02 & 0.10 & 0.16 \\
\hline
\end{tabular}

$8 \times 10^{17} \mathrm{~cm}^{-3}$. The detailed AlN composition $(x)$ in the p- $\mathrm{Al}_{x} \mathrm{Ga}_{1-x} \mathrm{~N}$ layer for VCSELs B1 to B3 can be found in Table 1.

Holes will encounter a large valence band offset $\left(\varphi_{1}\right)$ between the p-EBL and the p-GaN with the value of $159.10 \mathrm{meV}$ for VCSEL A [see Fig. 1(a)]. However, such valence band offset $\left(\varphi_{2}\right)$ can be reduced by using the p-EBL/p- $\mathrm{Al}_{x} \mathrm{Ga}_{1-x} \mathrm{~N}$ structure [see Fig. 1(b)]. The p- $\mathrm{Al}_{x} \mathrm{Ga}_{1-x} \mathrm{~N} / \mathrm{p}-\mathrm{GaN}$ structure enables the storage of the electric field due to the polarization feature for this junction, and the electric field in the p-GaN layer will increase the hole energy, which is able to suppress the hole blocking effect by the p- $\mathrm{Al}_{x} \mathrm{Ga}_{1-x} \mathrm{~N} / \mathrm{p}-\mathrm{GaN}$ interface [see Fig. 1(b)]. As a result, a compromised effect of the descending hole concentration in the $\mathrm{p}-\mathrm{Al}_{x} \mathrm{Ga}_{1-x} \mathrm{~N}$ layer and the reduced valence band offset at the $\mathrm{p}-\mathrm{EBL} / \mathrm{p}-\mathrm{Al}_{x} \mathrm{Ga}_{1-x} \mathrm{~N}$ interface can decrease the hole blocking effect by the p-EBL. Correspondingly, the hole injection efficiency into the MQWs can be enhanced for the proposed VCSELs.

To better illustrate the aforementioned point of view, in this work, the Photonic Integrated Circuit Simulator in 3D (PICS3D) is used to investigate the impact of the p-AlGaN/ p-GaN structure on the GaN-based VCSELs, which contains various equations such as Poisson's equation, rate equation, current continuity equation, carrier transport equation, and complex wave equation ${ }^{[15]}$. The Auger recombination is considered by setting the Auger recombination coefficient to $1.4 \times 10^{-43} \mathrm{~m}^{6} \cdot \mathrm{s}^{-1[16]}$. Considering the non-radiative recombination occurring at defects, the Shockley-Read-Hall (SRH) lifetime is set to be $1 \times 10^{-8} \mathrm{~s}^{[16]}$. In the meantime, we also consider a $40 \%$ polarization level for the [0001] oriented VCSEL structure ${ }^{[17,18]}$. The band-offset ratios for the InGaN/GaN and GaN/AlGaN heterojunctions are set to $0.70 / 0.30$ and 0.50 / 0.50 , respectively, which defines the ratio of the conduction band offset and the valence band offset ${ }^{[19,20]}$. The polarization level of $40 \%$ is assumed in our model for the GaN/AlGaN heterojunction $^{[21,22]}$. The average optical loss for the $\mathrm{p}-\mathrm{GaN}$ layer, the p-EBL, the MQWs, and the n-GaN layer in our modes is set to be $1000 \mathrm{~m}^{-1}$.

\section{Results and Discussion}

To probe the impact of the $\mathrm{p}-\mathrm{Al}_{x} \mathrm{Ga}_{1-x} \mathrm{~N} / \mathrm{p}-\mathrm{GaN}$ hole injection layer on the hole injection capability, we firstly demonstrate the longitudinal hole concentration profiles in the MQWs region for VCSEL A and VCSELs B1 to B3 in Fig. 2(a). It shows that the hole concentration for VCSELs B1 to B3 is higher than that for VCSEL A. It is worth noting that the hole concentration in the central aperture for VCSELs B1 to B3 is not remarkably 

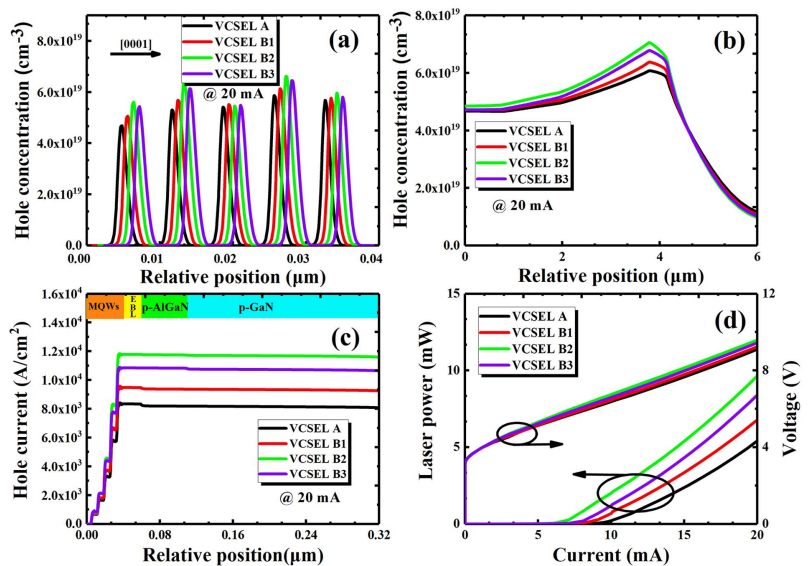

Fig. 2. (a) Hole concentration profiles in the MQWs region, (b) lateral distribution of hole concentration, and (c) hole injection current for VCSELS A and B1 to $B 3$ at $20 \mathrm{~mA}$. (d) Laser power and applied voltage in terms of the injection current for VCSELS A and B1 to B3.

increased when compared with VCSEL A, and this means that the current spreading effect for VCSELs B1 to B3 shall be further improved [see Fig. 2(b)]. However, this makes sense such that GaN-based VCSELs with lateral injection current schemes are challenged by the worse current spreading effect ${ }^{[23]}$. Once the $\mathrm{p}-\mathrm{AlGaN} / \mathrm{p}-\mathrm{GaN}$ structure is adopted, the vertical hole injection is significantly promoted before the holes can be laterally spread. However, the overall hole concentration in the active region can be increased by generating high-order laser beams. Then, we present the injection hole current for the three devices in Fig. 2(c), which shows that the hole injection current is increased greatly for VCSELs B1 to B3 when compared with VCSEL A. Therefore, the total laser power is enhanced for VCSELs B1 to B3 in Fig. 2(d). Meanwhile, Fig. 2(d) also indicates that the threshold current slightly decreases for VCSELs B1 to B3 due to the improved hole injection capability. However, if we compare VCSELs B1, B2, and B3, we find that the hole concentration, laser power, forward voltage, and hole injection current increase first and then decrease as the AlN composition of the $\mathrm{p}-\mathrm{Al}_{x} \mathrm{Ga}_{1-x} \mathrm{~N}$ layer increases. Therefore, the variations in the hole concentration, laser power, forward voltage, and hole injection current for VCSELs B1, B2, and B3 are closely associated with the $\mathrm{p}-\mathrm{Al}_{x} \mathrm{Ga}_{1-x} \mathrm{~N} / \mathrm{p}-\mathrm{GaN}$ structure.

As mentioned previously, the enhanced hole concentration in the MQWs and the improved laser power are attributed to the promoted hole injection capability, which is tentatively attributed to the electric field in the $\mathrm{p}-\mathrm{Al}_{x} \mathrm{Ga}_{1-x} \mathrm{~N} / \mathrm{p}-\mathrm{GaN}$ hole injection layer. Therefore, we present the electric field profiles in the $\mathrm{p}-\mathrm{Al}_{x} \mathrm{Ga}_{1-x} \mathrm{~N} / \mathrm{p}-\mathrm{GaN}$ heterojunction for VCSELs A, B1, B2, and $\mathrm{B} 3$ to further probe the impact of the $\mathrm{p}-\mathrm{Al}_{x} \mathrm{Ga}_{1-x} \mathrm{~N} / \mathrm{p}-\mathrm{GaN}$ hole injection layer on the hole transport, as shown in Fig. 3(a). We can clearly see that the electric field intensity in the p-GaN region for VCSEL A is smallest among the discussed VCSELs, especially at the p- $\mathrm{Al}_{x} \mathrm{Ga}_{1-x} \mathrm{~N} / \mathrm{p}-\mathrm{GaN}$ interface in Fig. 3(a). The smallest electric field intensity is attributed to the absence of negative polarization induced sheet charges at the
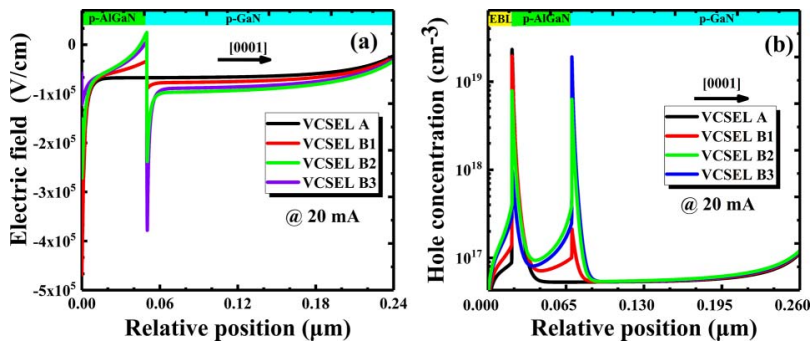

Fig. 3. (a) Electric field profiles in the $p-A l_{x} G_{1-x} N$ and $p-G a N$ layers for VCSELS $A, B 1, B 2$, and B3, (b) hole concentration profiles in the $p-E B L, p-A I_{x} G a_{1-x} N$, and p-GaN layers for VCSELs A, B1, B2, and B3, respectively. Data are calculated at the current of $20 \mathrm{~mA}$.

p- $\mathrm{Al}_{x} \mathrm{Ga}_{1-x} \mathrm{~N} / \mathrm{p}-\mathrm{GaN}$ interface for VCSEL A. Therefore, the electric field in the p-GaN layer only arises from the applied bias. Meanwhile, we find that the electric field intensity in the $\mathrm{p}-\mathrm{GaN}$ region becomes stronger with AlN composition in the p- $\mathrm{Al}_{x} \mathrm{Ga}_{1-x} \mathrm{~N}$ layer increasing to $0.02,0.10$, and 0.16 , respectively. Hence, the $\mathrm{p}-\mathrm{Al}_{x} \mathrm{Ga}_{1-x} \mathrm{~N} / \mathrm{p}-\mathrm{GaN}$ enables the storage of the electric field in the $\mathrm{p}-\mathrm{GaN}$ layer. However, it is worth noting that the electric field intensity in the $\mathrm{p}-\mathrm{Al}_{x} \mathrm{Ga}_{1-x} \mathrm{~N}$ layer is weaker for VCSELs B1 to B3 when compared with that for VCSEL A. Therefore, it is important to consider the compromised effect of the electric fields in $\mathrm{p}-\mathrm{Al}_{x} \mathrm{Ga}_{1-x} \mathrm{~N}$ and $\mathrm{p}-\mathrm{GaN}$ layers. By following $W=e \int_{0}^{L} E_{\text {field }} \mathrm{d} x$ ( $W, L$, and $E_{\text {field }}$ represent the obtained total energy for the holes, the integration range, and the electric field, respectively), we can get the energy that the holes obtain from the $\mathrm{p}$-AlGaN and $\mathrm{p}$-GaN layers, where the values are $-1.53 \mathrm{eV},-1.64 \mathrm{eV},-1.86 \mathrm{eV}$, and $-1.76 \mathrm{eV}$ for VCSELs A, B1, B2, and B3, respectively. Hence, the optimized VCSEL B2 with the $\mathrm{p}-\mathrm{Al}_{0.10} \mathrm{Ga}_{0.90} \mathrm{~N}$ structure can properly increase the hole energy to promote the hole injection. However, the comparison among VCSELs B1, B2, and B3 shows that when the AlN composition in the $\mathrm{p}-\mathrm{Al}_{x} \mathrm{Ga}_{1-x} \mathrm{~N}$ layer increases to 0.16 , the electric field intensity in the p-GaN region for VCSELs B1 and B3 becomes weaker than that for VCSEL B2. If we refer to Fig. 2(b), we find that the forward bias for VCSEL B3 becomes smaller than that for VCSEL B2, which is likely due to the increased hole concentration in the $\mathrm{p}-\mathrm{GaN}$ layer and enhances the electrical conductivity therein for VCSEL B ${ }^{[24]}$. To prove our point, we then show the hole concentration profiles in the p-EBL/ the $\mathrm{p}-\mathrm{Al}_{x} \mathrm{Ga}_{1-x} \mathrm{~N}$ heterojunction and $\mathrm{p}-\mathrm{GaN}$ layer for VCSELs A, B1, B2, and B3 in Fig. 3(b). The integrated hole concentration levels in the p-GaN layer are calculated to be $1.12 \times 10^{12} \mathrm{~cm}^{-2}$, $2.09 \times 10^{12} \mathrm{~cm}^{-2}$, and $3.25 \times 10^{12} \mathrm{~cm}^{-2}$ for VCSELs B1 to $\mathrm{B} 3$, respectively. The increased hole concentration in the p-GaN layer for VCSEL B3 may arise from the blocking effect by the increased valence band barrier height for the $\mathrm{p}-\mathrm{Al}_{0.16} \mathrm{Ga}_{0.84} \mathrm{~N} / \mathrm{p}-\mathrm{GaN}$. In order to further explore the impact of the blocking effect by the increased valence band barrier height for the $\mathrm{p}-\mathrm{Al}_{x} \mathrm{Ga}_{1-x} \mathrm{~N} / \mathrm{p}-\mathrm{GaN}$, we then calculate the integrated hole concentration levels in the $\mathrm{p}-\mathrm{Al}_{x} \mathrm{Ga}_{1-x} \mathrm{~N}$ layer, where the numbers are $3.38 \times 10^{12} \mathrm{~cm}^{-2}, 3.13 \times 10^{12} \mathrm{~cm}^{-2}$, $1.89 \times 10^{12} \mathrm{~cm}^{-2}$, and $7.95 \times 10^{11} \mathrm{~cm}^{-2}$ for VCSELs A, B1, 
$\mathrm{B} 2$, and $\mathrm{B} 3$, respectively. Therefore, the hole concentration in the $\mathrm{p}-\mathrm{Al}_{x} \mathrm{Ga}_{1-x} \mathrm{~N}$ layer is slightly lower for VCSELs $\mathrm{B} 1$ and B2 when compared with that for VCSEL A, although the valence band barrier height exists at the $\mathrm{p}-\mathrm{Al}_{x} \mathrm{Ga}_{1-x} \mathrm{~N} / \mathrm{p}-\mathrm{GaN}$ interface. However, the integrated hole concentration in the $\mathrm{p}-\mathrm{Al}_{0.16} \mathrm{Ga}_{0.84} \mathrm{~N}$ layer is the lowest in spite of the increased hole energy for VCSEL B3, which is likely attributed to the larger valence band barrier height for the $\mathrm{p}-\mathrm{Al}_{0.16} \mathrm{Ga}_{0.84} \mathrm{~N} / \mathrm{p}-\mathrm{GaN}$ interface, such that more holes are confined in the $\mathrm{p}-\mathrm{GaN}$ layer. Therefore, there is a tradeoff between the hole acceleration effect and the hole blocking effect for the $\mathrm{p}-\mathrm{Al}_{x} \mathrm{Ga}_{1-x} \mathrm{~N} / \mathrm{p}-\mathrm{GaN}$ design.

The other advantage for the proposed device is that the adoption of the $\mathrm{p}-\mathrm{Al}_{x} \mathrm{Ga}_{1-x} \mathrm{~N}$ layer can produce a $\mathrm{p}-\mathrm{EBL} /$ $\mathrm{p}-\mathrm{Al}_{x} \mathrm{Ga}_{1-x} \mathrm{~N}$ junction, and such a junction helps to reduce the valence band barrier height when compared with the $\mathrm{p}-\mathrm{EBL} / \mathrm{p}-\mathrm{GaN}$ junction. Thus, the hole injection capability in the MQWs from the $\mathrm{p}-\mathrm{Al}_{x} \mathrm{Ga}_{1-x} \mathrm{~N}$ layer can be enhanced. Then, we present the valence band profiles in the p-EBL/ p-GaN, p-EBL/p- $\mathrm{Al}_{0.02} \mathrm{Ga}_{0.98} \mathrm{~N}$, p-EBL/p- $\mathrm{Al}_{0.10} \mathrm{Ga}_{0.90} \mathrm{~N}$, and $\mathrm{p}-\mathrm{EBL} / \mathrm{p}-\mathrm{Al}_{0.16} \mathrm{Ga}_{0.84} \mathrm{~N}$ regions for VCSELs $\mathrm{A}, \mathrm{B} 1, \mathrm{~B} 2$, and $\mathrm{B} 3$ in Figs. 4(a) $-4(\mathrm{~d})$, respectively. According to Figs. 4(a) $-4(\mathrm{~d})$, we then demonstrate the valence band barrier heights of the p-EBL/p-GaN, p-EBL/p- $\mathrm{Al}_{0.02} \mathrm{Ga}_{0.98} \mathrm{~N}, \mathrm{p}-\mathrm{EBL} / \mathrm{p}-\mathrm{Al}_{0.10} \mathrm{Ga}_{0.90} \mathrm{~N}$, and $\mathrm{p}-\mathrm{EBL} / \mathrm{p}-\mathrm{Al}_{0.16} \mathrm{Ga}_{0.84} \mathrm{~N}$ junctions, which are $159.10 \mathrm{meV}$, $153.10 \mathrm{meV}, 86.20 \mathrm{meV}$, and $34.80 \mathrm{meV}$ for VCSELs A, B1, $\mathrm{B} 2$, and $\mathrm{B} 3$, respectively. Therefore, the $\mathrm{p}-\mathrm{EBL} / \mathrm{p}-\mathrm{Al}_{x} \mathrm{Ga}_{1-x} \mathrm{~N}$ junction enables a reduced hole blocking effect by the p-EBL [see Fig. 3(a)]. However, despite the smallest valence band barrier height of the $\mathrm{p}-\mathrm{EBL} / \mathrm{p}-\mathrm{Al}_{0.16} \mathrm{Ga}_{0.84} \mathrm{~N}$ junction for VCSEL $\mathrm{B} 3$, the lowest hole concentration in the $\mathrm{p}-\mathrm{Al}_{0.16} \mathrm{Ga}_{0.84} \mathrm{~N}$ layer [see Fig. 3(b)] sacrifices the hole injection into the MQW when compared with VCSELs B1 and B2. As a result, the compromised effect by both the hole concentration in the
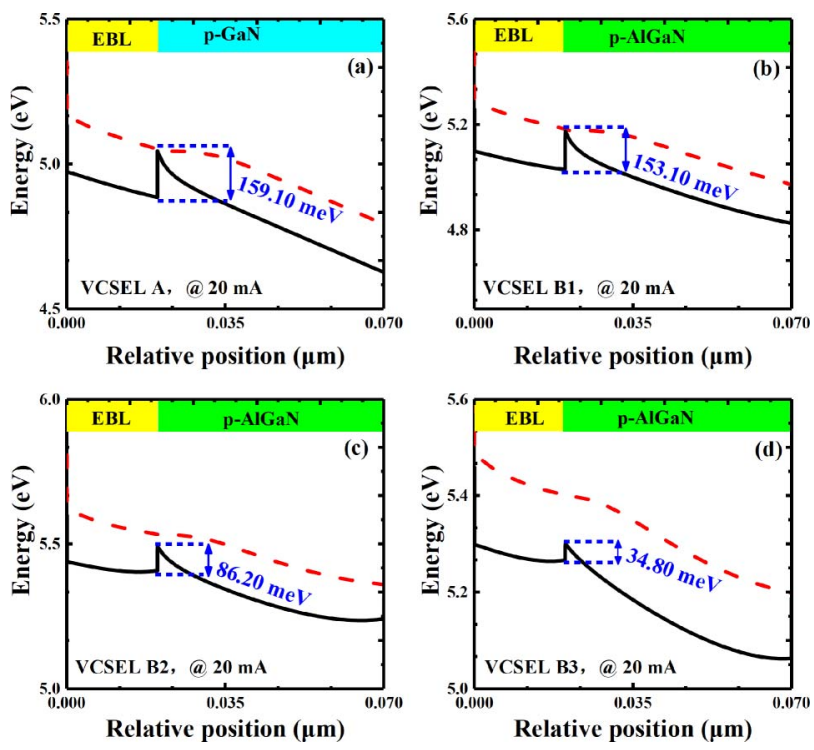

Fig. 4. Valence band profiles in the p-EBL and the $p$-AIGaN layers for (a) VCSEL A, (b) VCSEL B1, (c) VCSEL B2, and (d) VCSEL B3. Data are calculated at the current of $20 \mathrm{~mA}$.
$\mathrm{p}-\mathrm{Al}_{x} \mathrm{Ga}_{1-x} \mathrm{~N}$ layer and the valence band barrier height at the $\mathrm{p}-\mathrm{EBL} / \mathrm{p}-\mathrm{Al}_{x} \mathrm{Ga}_{1-x} \mathrm{~N}$ junctions promises the largest hole concentration in the MQWs for VCSEL B2 among the investigated devices.

Up to now, we have realized that using the optimized $\mathrm{p}-\mathrm{Al}_{x} \mathrm{Ga}_{1-x} \mathrm{~N} / \mathrm{p}-\mathrm{GaN}$ structure as the hole injection supplier will be able to improve the hole injection capability and enhance the laser power. Nevertheless, this design of multiple junctions may increase the parasitic capacitance for VCSELs B1 to B3 and decrease the modulation response capability. Therefore, it is necessary to present the impact of the designed VCSELs with the $\mathrm{p}-\mathrm{Al}_{x} \mathrm{Ga}_{1-x} \mathrm{~N} / \mathrm{p}-\mathrm{GaN}$ structure on the $3 \mathrm{~dB}$ frequency bandwidth. The calculated frequency response characteristics are presented in Figs. 5(a) and 5(b) for VCSELs A, B1, B2, and B3 at the injection current levels of $1 \mathrm{~mA}$ and $20 \mathrm{~mA}$, respectively. The insets of Figs. 5(a) and 5(b) demonstrate the $3 \mathrm{~dB}$ frequency bandwidth for the discussed VCSELs at the current levels of $1 \mathrm{~mA}$ and $20 \mathrm{~mA}$, respectively. If we compare Figs. 5(a) and 5 (b), we find that the $3 \mathrm{~dB}$ frequencies for all the discussed VCSELs are increased as the injection current increases. To better explain the variation trend of frequency response characteristics with the injection current increasing, we also show the stimulated radiative recombination rate $\left(R_{\text {sti }}\right)$ in the MQWs region for the discussed VCSELs at the current levels of $1 \mathrm{~mA}$ and $20 \mathrm{~mA}$ in Figs. 5(c) and 5(d), respectively. We can clearly see that the stimulated radiative recombination rate in the MQWs region at the current of $20 \mathrm{~mA}$ for VCSELs A, B1, B2, and $\mathrm{B} 3$ is higher than that at the current level of $1 \mathrm{~mA}$, such that all of the quantum wells can produce the stimulated recombination at the current level of $20 \mathrm{~mA}$, while the three quantum wells close to the $\mathrm{n}-\mathrm{GaN}$ layer side show the absorption at the current level of $1 \mathrm{~mA}$. The increased stimulated radiative recombination rate can reduce differential carrier lifetime, and this therefore
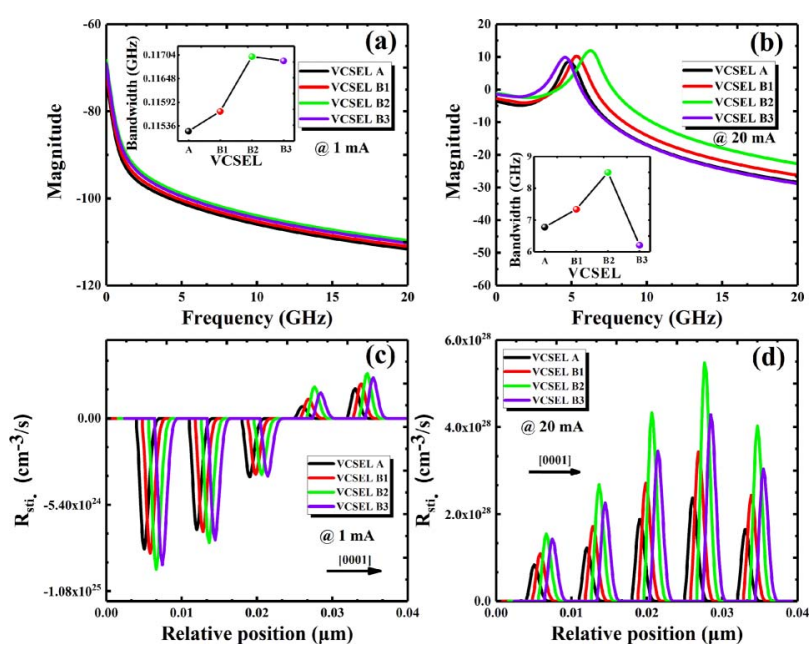

Fig. 5. Calculated small-signal modulation response at the current levels of (a) $1 \mathrm{~mA}$ and (b) $20 \mathrm{~mA}$ for VCSELS A, B1, B2, and B3. Stimulated radiative recombination rate $\left(R_{\mathrm{sti}}\right)$ in the MQWs at the currents of (c) $1 \mathrm{~mA}$ and (d) $20 \mathrm{~mA}$ for VCSELS A, B1, B2, and B3. Insets of (a) and (b) show $3 \mathrm{~dB}$ frequency bandwidth at the currents of $1 \mathrm{~mA}$ and $20 \mathrm{~mA}$, respectively. 
helps to increase the $3 \mathrm{~dB}$ frequency bandwidth. Therefore, Fig. 5(b) generally shows that the most increased laser power can maximize the $3 \mathrm{~dB}$ frequency bandwidth, which is due to the reduced differential carrier lifetime for VCSEL B2. Nevertheless, we also find that the $3 \mathrm{~dB}$ frequency bandwidth is the smallest for VCSEL B3 among the discussed VCSELs at the current of $20 \mathrm{~mA}$, although the stimulated radiative recombination rate for VCSEL B3 is increased when compared with that for VCSELs A and B1. This is mainly because the larger parasitic capacitance can be produced when the higher AlN composition is utilized in the $\mathrm{p}-\mathrm{Al}_{x} \mathrm{Ga}_{1-x} \mathrm{~N}$ for VCSEL B3.

\section{Conclusion}

To summarize, we have proposed and systematically analyzed the impact of different $\mathrm{p}-\mathrm{Al}_{x} \mathrm{Ga}_{1-x} \mathrm{~N} / \mathrm{p}-\mathrm{GaN}$ structures as the hole supplier on the hole injection capability, the laser power, and the $3 \mathrm{~dB}$ frequency bandwidth for GaN-based VCSELs. By using the $\mathrm{p}-\mathrm{Al}_{x} \mathrm{Ga}_{1-x} \mathrm{~N} / \mathrm{p}-\mathrm{GaN}$ heterojunction, the increased local electric field is produced in the $\mathrm{p}-\mathrm{GaN}$ layer, which is very useful for increasing the kinetic energy and the drift velocity for holes. Therefore, more holes can reach the $\mathrm{p}-\mathrm{Al}_{x} \mathrm{Ga}_{1-x} \mathrm{~N}$ layer. Meanwhile, the usage of the $\mathrm{p}-\mathrm{Al}_{x} \mathrm{Ga}_{1-x} \mathrm{~N}$ layer reduces the valence band barrier height in the p-EBL. As a result, the enhanced hole injection capability and the correspondingly increased laser power can both be achieved. However, more attention has to be paid such that the multiple p-EBL/ $\mathrm{p}-\mathrm{Al}_{x} \mathrm{Ga}_{1-x} \mathrm{~N} / \mathrm{p}-\mathrm{GaN}$ junctions may increase the parasitic capacitance, which will sacrifice the $3 \mathrm{~dB}$ frequency bandwidth in spite of the increased stimulated recombination rate. Therefore, the AlN composition for the $\mathrm{p}-\mathrm{Al}_{x} \mathrm{Ga}_{1-x} \mathrm{~N}$ layer has to be carefully set so that both the increased $3 \mathrm{~dB}$ frequency bandwidth and the enhanced laser power can be obtained. We believe that the proposed VCSEL structure in this work is very useful for making high-efficiency GaN-based VCSELs, and the device physics reported here is very important for the VCSEL community.

\section{Acknowledgement}

This work was supported in part by the National Natural Science Foundation of China (Nos. 62074050 and 61975051), Natural Science Foundation of Hebei Province (No. F2020202030), State Key Laboratory of Reliability and Intelligence of Electrical Equipment, Hebei University of Technology (No. EERI_PI2020008), Joint Research Project for Tunghsu Group and Hebei University of Technology (No. HI1909), and Guangdong Basic and Applied Basic Research Foundation (No. 2019A1515111053).

\section{References}

1. K. Iga, "Forty years of vertical-cavity surface-emitting laser: invention and innovation,” Jpn. J. Appl. Phys. 57, 08PA01 (2018).
2. A. A. Bergh, "Blue laser diode (LD) and light emitting diode (LED) applications," Phys. Stat. Sol. 201, 2740 (2004).

3. T. Hamaguchi, Y. Hoshina, K. Hayashi, M. Tanaka, M. Ito, M. Ohara, T. Jyoukawa, N. Kobayashi, H. Watanabe, M. Yokozeki, R. Koda, and K. Yanashima, "Room-temperature continuous-wave operation of green vertical-cavity surface-emitting lasers with a curved mirror fabricated on \{20-21\} semi-polar GaN," Appl. Phys. Express 13, 041002 (2020).

4. A. Liu, P. Wolf, J. A. Lott, and D. Bimberg, "Vertical-cavity surfaceemitting lasers for data communication and sensing," Photonics Res. 7, 121 (2019)

5. Y. Higuchi, K. Omae, H. Matsumura, and T. Mukai, "Room-temperature CW lasing of a GaN-based vertical-cavity surface-emitting laser by current injection," Appl. Phys. Express 1, 121102 (2008).

6. G. Cosendey, A. Castiglia, G. Rossbach, J.-F. Carlin, and N. Grandjean, "Blue monolithic AlInN-based vertical cavity surface emitting laser diode on freestanding GaN substrate," Appl. Phys. Lett. 101, 151113 (2012).

7. R. T. ElAfandy, J.-H. Kang, B. Li, T. K. Kim, J. S. Kwak, and J. Han, "Roomtemperature operation of $c$-plane GaN vertical cavity surface emitting laser on conductive nanoporous distributed Bragg reflector," Appl. Phys. Lett. 117, 011101 (2020).

8. J. T. Leonard, E. C. Young, B. P. Yonkee, D. A. Cohen, T. Margalith, S. P. DenBaars, J. S. Speck, and S. Nakamura, "Demonstration of a III-nitride vertical-cavity surface-emitting laser with a III-nitride tunnel junction intracavity contact," Appl. Phys. Lett. 107, 091105 (2015).

9. M. Kuramoto, S. Kobayashi, T. Akagi, K. Tazawa, K. Tanaka, T. Saito, and T. Takeuchi, "Enhancement of slope efficiency and output power in GaN-

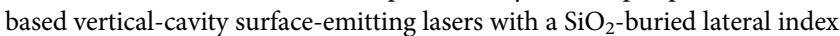
guide," Appl. Phys. Lett. 112, 111104 (2018).

10. M. Kuramoto, S. Kobayashi, T. Akagi, K. Tazawa, H. Tanaka, and T. Takeuchi, "Nano-height cylindrical waveguide in GaN-based verticalcavity surface-emitting lasers," Appl. Phys. Express 13, 082005 (2020).

11. S. Lee, C. A. Forman, J. Kearns, J. T. Leonard, D. A. Cohen, S. Nakamura, and S. P. DenBaars, "Demonstration of GaN-based vertical-cavity surfaceemitting lasers with buried tunnel junction contacts," Opt. Express 27, 31621 (2019).

12. X. Qiu, Y. Zhang, S. Hang, Y. Gao, J. Kou, K. Tian, Q. Zheng, Q. Li, and Z. H. Zhang, "Enhancing the lateral current injection by modulating the doping type in the p-type hole injection layer for InGaN/GaN vertical cavity surface emitting lasers," Opt. Express 28, 18035 (2020).

13. D. H. Hsieh, A. J. Tzou, T. S. Kao, F. I. Lai, D. W. Lin, B. C. Lin, T. C. Lu, W. C. Lai, C. H. Chen, and H. C. Kuo, "Improved carrier injection in GaNbased VCSEL via AlGaN/GaN multiple quantum barrier electron blocking layer," Opt. Express 23, 27145 (2015).

14. B. C. Lin, Y. A. Chang, K. J. Chen, C. H. Chiu, Z. Y. Li, Y. P. Lan, C. C. Lin, P. T. Lee, Y. K. Kuo, M. H. Shih, H. C. Kuo, T. C. Lu, and S. C. Wang, "Design and fabrication of a InGaN vertical-cavity surface-emitting laser with a composition-graded electron-blocking layer," Laser Phys. Lett. 11, 085002 (2014).

15. https://crosslight.com.cn/wordpress/products/pics3d.

16. P. Mackowiak and W. Nakwaski, "Designing guidelines for possible continuous-wave-operating nitride vertical-cavity surface-emitting lasers," J. Phys. D 33, 642 (2000).

17. V. Fiorentini, F. Bernardini, and O. Ambacher, "Evidence for nonlinear macroscopic polarization in III-V nitride alloy heterostructures," Appl. Phys. Lett. 80, 1204 (2002).

18. Z.-H. Zhang, S. Tiam Tan, Z. Kyaw, Y. Ji, W. Liu, Z. Ju, N. Hasanov, X. Wei Sun, and H. Volkan Demir, "InGaN/GaN light-emitting diode with a polarization tunnel junction," Appl. Phys. Lett. 102, 193508 (2013).

19. Y.-K. Kuo, B.-T. Liou, M.-L. Chen, S.-H. Yen, and C.-Y. Lin, "Effect of bandoffset ratio on analysis of violet-blue InGaN laser characteristics," Opt. Commun. 231, 395 (2004).

20. W. Wang, C. Chu, J. Che, S. Hang, H. Shao, K. Tian, Y. Zhang, and Z.-H. Zhang, "Is a thin p-GaN layer possible for making high-efficiency AlGaN-based deep-ultraviolet light-emitting diodes?” Opt. Express 29, 29651 (2021).

21. D. Zhang, C. Chu, K. Tian, J. Kou, W. Bi, Y. Zhang, and Z.-H. Zhang, "Improving hole injection from $\mathrm{p}$-EBL down to the end of active region by simply playing with polarization effect for AlGaN based DUV lightemitting diodes," AIP Adv. 10, 065032 (2020). 
22. C. Chu, K. Tian, J. Che, H. Shao, J. Kou, Y. Zhang, Z.-H. Zhang, and H.-C. Kuo, "On the impact of electron leakage on the efficiency droop for AlGaN based deep ultraviolet light emitting diodes," IEEE Photonics J. 12, 1600207 (2020).

23. V. P. Kalosha, V. A. Shchukin, N. Ledentsov, and N. N. Ledentsov, "Comprehensive analysis of electric properties of oxide-confined vertical-cavity surface-emitting lasers," IEEE J. Sel. Top. Quantum Electron. 25, 1700809 (2019).

24. F. Huang, X. Jia, Y. Liu, K. Tian, C. Chu, Q. Zheng, Y. Zhang, Z. Xin, Z.-H. Zhang, and Q. Li, "Advances of beveled mesas for GaN-based trench Schottky barrier diodes," AIP Adv. 11, 045316 (2021). 